MATEC Web of Conferences 3, 01059 (2013)

DOI: $10.1051 /$ matecconf/20130301059

(C) Owned by the authors, published by EDP Sciences, 2013

\title{
Determination of the surface tension of mixtures with molecular simulation
}

\author{
J.C. Neyt ${ }^{1,2}$, A. Wender ${ }^{1}$, V. Lachet ${ }^{1}$, and P. Malfreyt ${ }^{2}$ \\ ${ }^{1}$ IFP Energies nouvelles, 1-4 avenue de Bois Préau, 92852 Rueil-Malmaison, France \\ ${ }^{2}$ Clermont Université, Université Blaise Pascal, Institut de Chimie de Clermont-Ferrand, BP 10448, F-63000 \\ Clermont-Ferrand, France
}

Determine the interfacial tension between phases is an important task in many scientific fields. In the oil industry and its derivatives, many immiscible phases are in contact. The surface tension existing between these phases can have serious consequences. This lets you know what maximum quantity of gas can be stored in geological reservoirs. Also, the surface tension management allows to optimize the performance of petrol farms. Thus, it is necessary to know with precision the values of surface tension for mixtures.

Predictives models exist for these values, but only for pure or simple mixtures (parachors or gradient theory for exemple). To optimize those models or to develop others, we must have more data on more complex mixtures (more than three constituant, presence of salt in liquids, surfactants effects,...). However, the experimental determination of interfacial tension of mixtures at high temperatures and pressures involves many problems. It is in this context that the molecular simulation is used : to predict values of surface tension which are difficulf to obtain with experimental measurements. From interaction potentials parameterized on experimental measurements, molecular simulation can predict interfacial tension values for extremely varied mixtures, even under conditons of elevated temperature and pressure. These methods are now proven and are now optimised to phase equilibria of liquids and their vapors, liquids and gases, or even between two liquid phases.

We propose to illustrate those methods with differents systems : interfaces between liquid water and different mixtures of gaz (methane and nitrogen), interfaces between brines and their water vapor, and also for interfaces between a liquid alkane and liquid water, and see the effect on the calculated surface tension of adding an alcohol to the interface (methanol or propanol). 